\title{
Depolarizing effect of neocortical chandelier neurons
}

\author{
Alan Woodruff ${ }^{*}$, Qing $\mathrm{Xu}^{2}$, Stewart A. Anderson ${ }^{2}$ and Rafael Yuste ${ }^{1}$ \\ 1 Howard Hughes Medical Institute, Department Biological Sciences, Columbia University, New York, NY, USA \\ 2 Department Psychiatry, Weill Cornell Medical College, New York, NY, USA
}

\author{
Edited by: \\ David Linden, Johns Hopkins \\ University, USA

\section{Reviewed by:} \\ Gianmaria Maccaferri, Northwestern \\ University, USA \\ Michael Brecht, Humboldt \\ University Berlin, Germany

\section{*Correspondence:} \\ Alan Woodruff, Department Biological \\ Sciences, Columbia University, 1212 \\ Amsterdam Avenue, Box 2435 , \\ New York, NY 10027, USA \\ e-mail:aw2343@columbia.edu
}

Chandelier (or axo-axonic) cells are one of the most distinctive types of GABAergic interneurons in the cortex. Although they have traditionally been considered inhibitory neurons, data from rat and human neocortical preparations suggest that chandelier cells have a depolarizing effect on pyramidal neurons at resting membrane potential, and could even activate synaptic chains of neurons. At the same time, recent results from rat hippocampal chandeliers indicate a predominantly inhibitory effect on their postsynaptic targets. To better understand the function of chandelier neurons, we generated Nkx2.1Cre MADM mice, a strain of genetically engineered animals that, by expressing GFP in a subset of neocortical interneurons, enable the identification and targeting of chandelier cells in living brain slices. Using these mice, we characterized the basic electrophysiological properties of a homogeneous population of chandelier neurons from upper layers of somatosensory cortical slices. These chandelier cells have characteristic axon cartridges and stereotypical electrophysiological features, distinguishable from basket cells. To investigate the effect of chandelier cells on target neurons, we performed paired recordings from chandeliers and postsynaptic pyramidal cells. In both perforated patch and cell-attached configurations, chandelier PSPs have in every case a reversal potential that is depolarized from rest. Our results support the idea that chandelier cells depolarize pyramidal neurons and could potentially have an excitatory effect on the network at rest.

Keywords: axo-axonic, GABA, axon initial segment, parvalbumin, Nkx2.1, MADM

\section{INTRODUCTION}

Chandelier cells are one of the most distinctive types of GABAergic interneurons present in cortical circuits. These cells have a distinctive axonal arbor, with parallel arrays of short vertical sets of presynaptic terminals ('cartridges'), which resemble the candlesticks of a chandelier lamp. Chandelier cells are rare and were only first described in the 1970s (Szentagothai and Arbib, 1974; Jones, 1975; Szentagothai, 1975). They form perhaps only a few percent of all GABAergic interneurons (Inda et al., 2007), and, distinctively, contact the axon initial segment of pyramidal cells (Somogyi, 1977; Fairen and Valverde, 1980; DeFelipe et al., 1985). Because of this, the terms chandelier cells and axo-axonic cells are used interchangeably.

Due to their striking morphologies, chandelier neurons are often used as the best example to illustrate the purposeful design of cortical microcircuits. A single chandelier cell contacts a large number of pyramidal neurons, and each chandelier cartridge establishes many strategically placed synapses on the axon initial segment, where the action potential is generated. Thus, chandelier cells appear ideally suited to shut off populations of pyramidal neurons, making chandelier cells potentially act as circuit switches.

In spite of all of this, little is known about the function of chandelier cells, due to their rarity in the cortical network and the lack of known unique neurochemical and physiological markers. Chandelier neurons have been occasionally recorded from slice preparations, and display fast-spiking (FS) characteristics (Buhl et al., 1994; Tamas and Szabadics, 2004; see Ascoli et al., 2008 for firing pattern definitions). Occasional in vivo recordings show that hippocampal chandelier cells have distinct firing patterns during theta and sharp wave oscillations (Klausberger et al., 2003) and that recruitment of neocortical chandelier cells can occur following whisker deflection (Zhu et al., 2004).

Although chandeliers have traditionally been considered inhibitory neurons, whole-cell recordings from rat and human neocortical slice preparations indicate that they can have a depolarizing effect on pyramidal neurons at resting membrane potential, even leading to the activation of synaptic chains of neurons (Szabadics et al., 2006; Molnar et al., 2008). This depolarizing effect, observed with perforated patch recordings in order to avoid altering the chloride equilibrium potential in the postsynaptic neurons, could be mediated by local differences in the expression of the $\mathrm{Na}-\mathrm{K}-2 \mathrm{Cl}$ transporter NKCC1 (Khirug et al., 2008). A depolarizing effect of chandelier cells might also explain the paradoxical existence of EPSPs that are sensitive to GABAergic blockers in the basolateral amygdala (Woodruff et al., 2006). At the same time, it is important to note that, aside from direct suprathreshold excitation, it is not clear if depolarizing IPSPs from chandelier cells could actually be excitatory, i.e., lead to spiking. It remains possible that conductance effects could counteract and even outweigh the depolarization.

Although these results suggests a depolarizing function for chandelier cells in the quiescent circuit, recent data from rat hippocampal chandelier neurons indicate a predominantly hyperpolarizing effect on their postsynaptic targets (Glickfeld et al., 2009). This recent study, performed with field potential electrodes in order not to perturb the intracellular milieu of the cell, did not detect a significant difference in postsynaptic responses in the pyramidal neurons, regardless of whether the GABAergic 
synapses where located at the somata or at the axon initial segment. Nevertheless, in this same study there was occasional evidence for polysynaptic excitatory events triggered by the stimulation of chandelier cells.

Thus, at present, the function of chandelier cells is controversial. Even the basic question of whether they depolarize or hyperpolarize their targets is not agreed upon. To examine this issue more closely, we have taken advantage of the recent progress in the understanding of interneuron developmental determination (Xu et al., 2004) and have generated a genetically modified strain of mice, in which a sublineage of interneurons that include chandelier cells is labeled (Xu et al., 2008). In these animals, one can reliably find and target chandelier cells in living brain slices. This enables, for the first time, systematic physiological experiments with a homogeneous population of chandelier neurons, and has allowed us to find reliable methods of distinguishing basket and chandelier cells on the basis of electrophysiological parameters (but see Xu and Callaway, 2009; Zaitsev et al., 2009). In addition, using two different recording conditions, perforated patch and cell-attached recordings, we find that all chandeliers studied have a depolarizing effect on pyramidal cells at rest. Our results are consistent with a predominantly depolarizing effect from resting membrane potential.

\section{MATERIALS AND METHODS GENERATION OF Nkx2.1 MADM MICE}

We used Nkx2.1Cre MADM mice, a novel strain of genetically engineered animals that express GFP in a subset of neocortical interneurons, including chandelier cells. These mice were generated using the MADM mosaic lineage strategy (Zong et al., 2005). MADM is a mammalian version of the MARCM technique, in which mitotic recombination, induced by the expression of a Flp recombinase, results in the selective expression of GFP in clones of cells (Luo, 2007). In Nkx2.1Cre MADM mice, clones of cells derived from progenitors that express the transcription factor $\mathrm{Nkx} 2.1$ are uniquely labeled by GFP, after Cre-mediated interchromosomal recombination (Figure 1A). Nkx2.1 is a homeodomain transcription factor selectively expressed in the Medial Ganglionic Eminence (MGE) in early development, a key anlage of forebrain interneurons (Lavdas et al., 1999; Wichterle et al., 1999; Xu et al., 2004, 2008).

Specifically, we used three mouse lines to generate Nkx2.1-Cre MADM mice (Figure 1A): Nkx2.1-Cre, MADM-5'GFP(Loxp)3'RFP (GR mouse in abbreviation) and MADM-5'RFP(Loxp)3'GFP (RG). GR and RG are alleles in the ROSA26 locus on chromosome 6 and are maintained as separate lines. In mice containing both the GR and the RG alleles, some cells expressing the Nkx2.1 driven Cre recombinase will undergo interchromosomal recombination, resulting in the generation of complete, and functional, GFP and RFP sequences, which are then segregated and expressed in different alleles. The result is the specific labeling of clones of Nkx2.1 expressing neurons with GFP and RFP (if recombination occurred either prior to or after cell cycle exit) or either GFP or RFP (if recombination occurred prior to cell cycle exit). Thus, the result is the specific labeling of clones of Nkx2.1 expressing neurons with GFP and/or RFP. Despite the predicted rarity of the interchromosomal recombination event, in nearly every animal a substantial proportion of GFP-neurons are chandelier cells. The
A

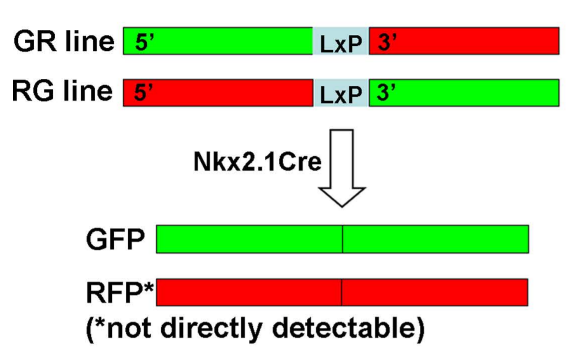

B

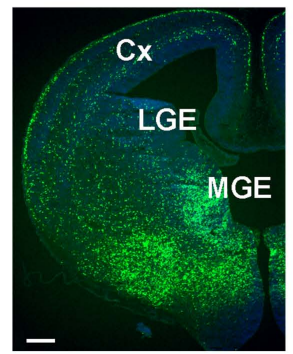

PV
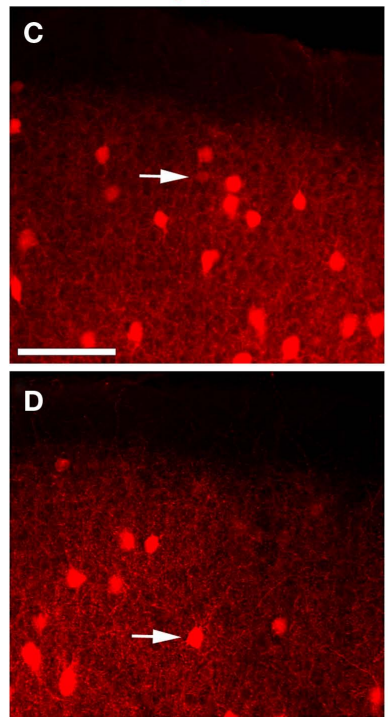

GFP PV
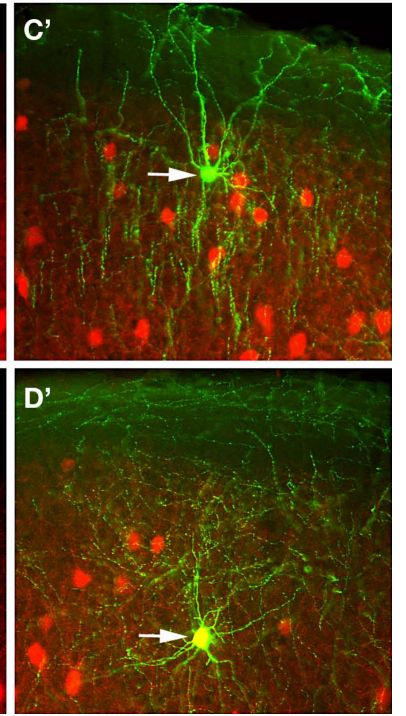

FIGURE 1 | Identification of chandelier cells from Nkx2.1 MADM mice. (A) Genetic strategy. MADM GFP-5', RFP-3' (GR line), and RFP-5', GFP-3', were crossed to $\mathrm{Nkx2.1Cre} \mathrm{mice} \mathrm{to} \mathrm{generate} \mathrm{mice} \mathrm{that} \mathrm{express} \mathrm{directly} \mathrm{visualizable}$ GFP fluorescence in sub-populations of Nkx2.1-lineage interneurons. (B) Section from an embryonic day (E) $14.5 \mathrm{Nk}$ 2.1Cre:Z/EGFP reporter mouse. Recombination from this reporter is far more frequent than in the MADM system (see Xu et al., 2008), and the panel illustrates the robust migration of recombined cells from the ventral telencephalic proliferative zone of the medial ganglionic eminence (MGE) to the cortex (CX). (C,D) Identification of chandelier and basket cells in Nkx2.1Cre:MADM mice. Immunofluorescence labeling for parvalbumin (PV; C,D) and GFP (C','D') from a section of Nkx2.1Cre:MADM cortex at P25. (C') This cell has a typical chandelier cell morphology, with generally straight, vertically oriented axon terminals, and weakly co-labels for PV [arrow in (C)]. (D') This cell has a typical basket cell morphology, with predominantly curved axon terminals, and strongly expresses PV [arrow in (D)]. LGE-lateral ganglionic eminence. Scale bar $=100 \mu \mathrm{m}$. 
rest of the labeled cells appear to be mainly parvalbumin-positive basket cells, as well as somatostatin-positive and neurogliaform interneurons. These mice therefore provide a genetic handle on chandelier cells, and enable their identification in living tissue. For brevity, in the rest of this manuscript we refer to the Nkx2.1Cre MADM GFP/RFP mice as Nkx2.1 mice.

\section{SLICE PREPARATION AND WHOLE-CELL RECORDINGS}

Animal handling and experimentation was done according to NIH and local IACUC guidelines. Nkx2.1Cre MADM mice (P15-23) were quickly decapitated and $300 \mu \mathrm{m}$ coronal slices prepared using a Leica VT1200-S vibratome. The cutting solution contained (in $\mathrm{mM}): 27 \mathrm{NaHCO}_{3}, 1.5 \mathrm{NaH}_{2} \mathrm{PO}_{4}, 222$ Sucrose, $2.6 \mathrm{KCl}, 3 \mathrm{MgSO}_{4}, 0.5$ $\mathrm{CaCl}_{2}$. Slices were incubated for $30 \mathrm{~min}$ at $32^{\circ} \mathrm{C}$ in an oxygenated $\left(95 \% \mathrm{O}_{2}\right.$ and $\left.5 \% \mathrm{CO}_{2}\right)$ artificial cerebrospinal fluid (ACSF, $\mathrm{pH}=7.4$ ) solution containing (in $\mathrm{mM}$ ): $126 \mathrm{NaCl}, 3 \mathrm{KCl}, 3 \mathrm{MgSO}_{4}, 1 \mathrm{CaCl}_{2}$, $1.1 \mathrm{NaH}_{2} \mathrm{PO}_{4}, 26 \mathrm{NaHCO}_{3}$, and 10 dextrose. Slices were allowed to equilibrate for at least a further $30 \mathrm{~min}$ at room temperature before being transferred to the recording chamber. The ACSF used for recording contained (in $\mathrm{mM}$ ): $126 \mathrm{NaCl}, 3 \mathrm{KCl}, 1.5 \mathrm{MgSO}_{4}$, $2.5 \mathrm{CaCl}_{2}, 1.1 \mathrm{NaH}_{2} \mathrm{PO}_{4}, 26 \mathrm{NaHCO}_{3}$, and 10 dextrose. Recordings were performed at $34-36^{\circ} \mathrm{C}$ using Multiclamp $700 \mathrm{~B}$ amplifiers (Molecular Devices). Whole-cell pipettes contained a solution with (in mM): $135 \mathrm{~K}$-methylsulfate, $8 \mathrm{NaCl}, 10$ HEPES, 2 MgATP, 0.3 NaGTP, 7 phosphocreatine, adjusted to $\mathrm{pH} 7.3$ with $1 \mathrm{M} \mathrm{KOH}$. On occasion, 50-100 $\mu \mathrm{M}$ Alexa594 was included in the pipette solution to aid cell identification. Rheobase is defined here as the minimal current of $500 \mathrm{~ms}$ duration required to evoke an action potential, and was assessed with current delivered in $10 \mathrm{pA}$ increments. Linear fits to subthreshold current-voltage relationships (Figures $2 \mathrm{C}, \mathbf{F}$ ) were fit over the range from resting membrane potential to $-55 \mathrm{mV}$. Statistical significance was assessed using paired or unpaired Student's $t$-tests. All data are presented as mean \pm SD.

\section{GRAMICIDIN-PERFORATED PATCHES}

Recording pipettes (3-5 M ) were filled with a solution containing (in $\mathrm{mM}$ ): $140 \mathrm{KCl}, 10 \mathrm{NaCl}, 10 \mathrm{HEPES}$ and $20-25 \mu \mathrm{g} / \mathrm{ml}$ gramicidin (Sigma-Aldrich), adjusted to $\mathrm{pH} 7.3$ with $1 \mathrm{M} \mathrm{KOH}$. Gramicidin was prepared as a stock solution at $5 \mathrm{mg} / \mathrm{ml}$ and sonicated before being diluted into the pipette solution. The same solution, without gramicidin, was used to tip-fill pipettes. Both solutions were kept on ice for the duration of experiments. Following formation of a gigaseal, perforation was assessed by continuously presenting $10 \mathrm{mV}$ test pulses to a cell voltage-clamped at $-70 \mathrm{mV}$, while recording series resistance. Recordings were begun once this value was below $80 \mathrm{M} \Omega$ (all data presented from cells with $\mathrm{R}_{\text {series }} 40-80 \mathrm{M} \Omega$ ). All gramicidin recordings were performed in current clamp. Prior to recording, the bridge balance was manually adjusted to the appropriate value after evaluating $\mathrm{R}_{\text {series }}$ in voltage clamp, and this procedure was performed intermittently throughout the duration of recording. Recordings were terminated upon gaining whole-cell access, a common occurrence. In these instances, membrane rupture was detected either by a spontaneous depolarization $(6.2 \pm 1.6 \mathrm{mV}$; $n=6$ ), reflecting the Donnan potential between pipette and cell interior (Kim and Trussell, 2007), or more commonly by the emergence of large $(>2 \mathrm{mV})$ spontaneous postsynaptic potentials and a decrease in series resistance (to $<30 \mathrm{M} \Omega$ ). These large events are presumably spontaneous GABAergic events that emerge following dialysis of the cell with the high $\mathrm{Cl}^{-}$pipette solution. The Donnan potential was partially offset by a calculated liquid junction potential of $3.4 \mathrm{mV}$. The recorded membrane potential in gramicidin recordings therefore reads $2.8 \mathrm{mV}$ more hyperpolarized than the true membrane potential, and values presented here have been corrected for this discrepancy. For determining $E_{\mathrm{GABA}}$, we varied the postsynaptic holding potential in steps of $\sim 5 \mathrm{mV}$ while activating the presynaptic interneuron. In some cases, a zero amplitude response did not coincide with any of the postsynaptic holding potentials. In these instances, $E_{\mathrm{GABA}}$ was estimated as lying immediately between a hyperpolarizing and depolarizing response. Although this approach is potentially subject to some experimenter bias, any such bias is likely to be small due to the relatively small steps in holding potential used.

\section{TIGHT-SEAL CELL-ATTACHED PATCHES}

Cell-attached pipettes (3-7 M $\Omega$ ) were filled either with the ACSF solution described above, or with $150 \mathrm{mM} \mathrm{NaCl}(\mathrm{pH}=7.4)$. We initially used ACSF, but frequently found breakthrough into whole-cell mode. We therefore also tested the $\mathrm{NaCl}$ solution, although no difference in maintaining membrane integrity was noticed. Using $\mathrm{NaCl}$ in the cell-attached pipette may affect the cell's resting membrane potential due to a local lack of extracellular $\mathrm{K}^{+}$ ions. In the region of the patch, $E_{\mathrm{K}}$ would then be expected to shift to negative infinity. This would in turn shift the resting membrane potential of the cell to more negative values, potentially creating artificially depolarizing GABA responses. However, we noticed no difference in the measured baseline membrane potential in cell-attached recordings with $\mathrm{NaCl}(-87.1 \mathrm{mV}, n=1)$ or ACSF $(-88.4 \pm 2.0 \mathrm{mV}, n=3)$. Furthermore, three of the four depolarizing responses observed in cell-attached mode were recorded with ACSF in the pipette.

Another potential concern with using $\mathrm{NaCl}$ in the pipette rather than ACSF is the lack of a buffer, such that $\mathrm{pH}$ changes that may occur in response to neural activity could have a larger, longer lasting impact on $\mathrm{pH}$-sensitive channels. Of concern in the present study is the sensitivity of both $\mathrm{GABA}_{\mathrm{A}}$ and $\mathrm{K}^{+}$channels to changes in $\mathrm{pH}$ (Chesler and Kaila, 1992). However, previous reports indicate an effect of $\mathrm{pH}$ on $\mathrm{GABA}_{\mathrm{A}}$ channel conductance, rather than on voltage sensitivity (Pasternack et al., 1992). This is therefore not of major concern in the current study, particularly since any affected $\mathrm{GABA}_{\mathrm{A}}$ channels would be somatic rather than axonal. $\mathrm{pH}$-dependent changes in $\mathrm{K}^{+}$channel activity could impact $E_{\mathrm{GABA}}$ by altering the activity of cation chloride cotransporters. However, even if this occurred in our situation, the effect would be on somatic $E_{\mathrm{GABA}}$ rather than axonal $E_{\mathrm{GABA}}$, which evidence suggests are maintained quite separately (Khirug et al., 2008).

Finally, given the small region of cell membrane covered by our cell-attached pipette, and the essentially infinite volume of $\mathrm{NaCl}$ in the pipette, we think it unlikely that $\mathrm{pH}$ changes occurring in our buffer-less solution will adversely affect the recording in any way. Intentional or unintentional breakthrough to whole-cell mode was detected by a large decrease in series resistance (from $>2 \mathrm{G} \Omega$ to $<30 \mathrm{M} \Omega$ ) and/or the appearance of frequent large, depolarizing GABAergic PSPs, similar to gramicidin recordings. In cellattached recordings, the recorded membrane potential reflects in 
A

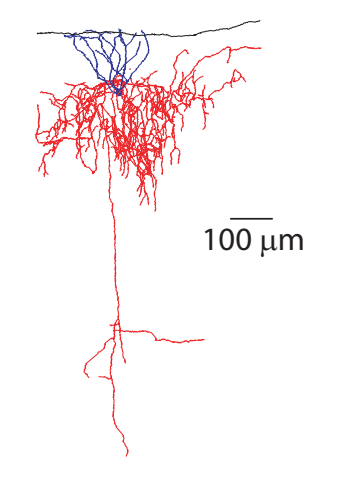

D

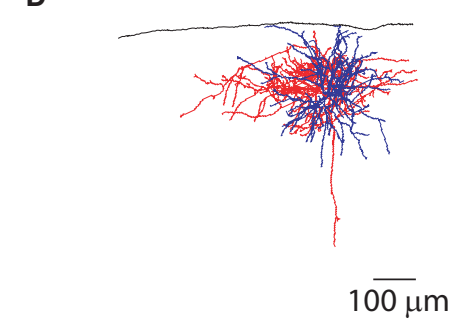

B
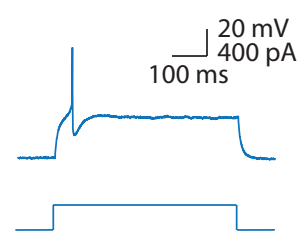

C
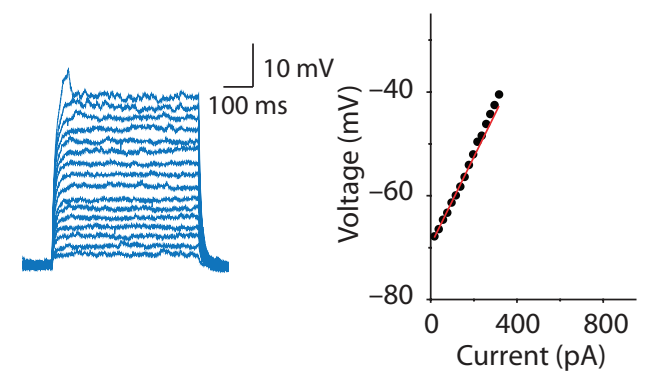

E

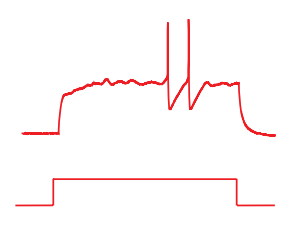

F

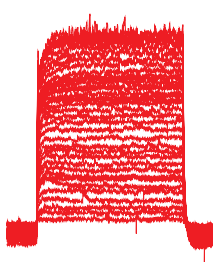

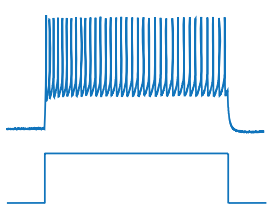
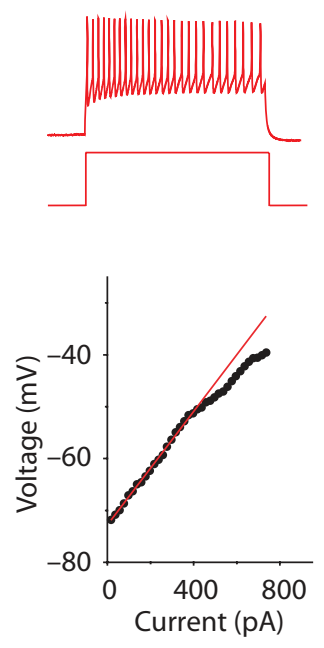

G

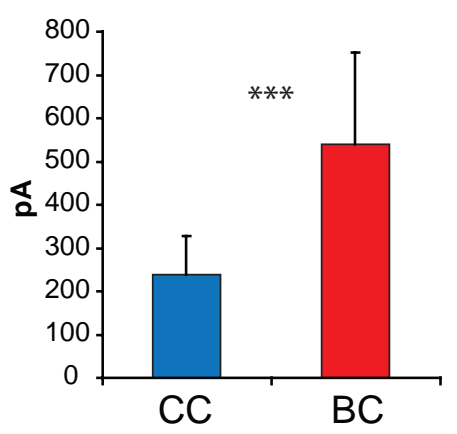

H

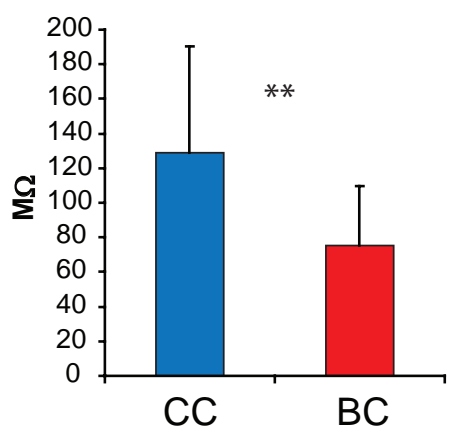

I

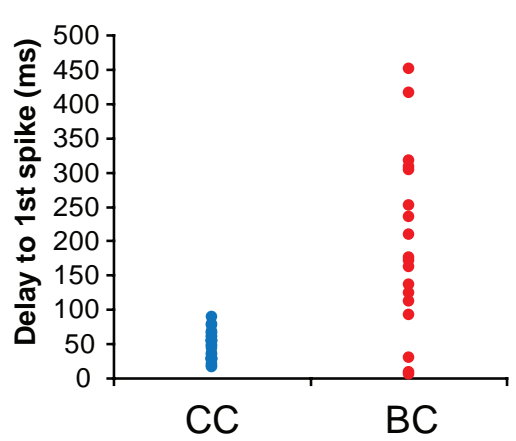

FIGURE 2 | Electrophysiological characterization of Nkx2 chandelier and basket cells. (A) Camera lucida reconstruction of the chandelier cell recorded from in (B,C). Blue lines indicate dendrites, red lines indicate axon, black lines show pial surface and light blue lines white matter border. (B) Threshold (left) and twice-threshold (right) response of a chandelier cell to somatic current injection. (C) Subthreshold current-voltage relationship. (D-F) As for (A-C), for basket cells. (G-I) Comparison of rheobase (G), input resistance $(\mathbf{H})$ and first spike latency (I) for the two cell types. Error bars represent SD. ${ }^{* *}: p<0.001 ;{ }^{* *}: p<0.01$. large part the magnitude of the seal resistance: as seal resistance increases, the recorded potential becomes more negative, due to less current leak through the seal resistance (Perkins, 2006). We therefore used the negativity of the membrane potential as a proxy for seal quality, and did not attempt to record until this value was below $-70 \mathrm{mV}$. No current was ever passed through the cell-attached pipette, such that the cell remained at its resting membrane potential. 


\section{RESULTS IDENTIFICATION OF CHANDELIER CELLS IN Nkx2.1 MICE}

We used brain slices from the somatosensory cortex of p15-23 Nkx2.1 mice (see Materials and Methods; Figure 1A). These mice express GFP in interneurons derived from the MGE (Figure 1B), a group which includes parvalbumin and somatostatin-positive neurons, among others (Xu et al., 2004, 2008). In neocortical brain slices from these animals we were able to visualize, from the GFP fluorescence, vertically oriented structures that appeared to be the axonal cartridges indicative of cortical chandelier cells (Figures 1C,C'). These structures were most noticeable in upper layer $2 / 3$, and we therefore targeted neurons near the border of layers 1 and 2/3. Indeed, when patching $\mathrm{Nkx} 2.1$ positive neurons at the layer 1-2 border and filling them with either Alexa594 or biocytin, we found that a significant number of them (>50\%) had typical chandelier morphologies (Figure 2A). The rest had axonal arbors with nested terminals, characteristic of basket cells (Figures 1D,D' and $2 \mathrm{D}$ ). For the rest of the study we recorded from interneurons, either chandelier or basket cells, located at the layer 1-2 border.

\section{INTRACELLULAR RESPONSES OF CHANDELIER AND BASKET CELLS}

The majority of recorded neurons exhibited the FS phenotype typical of parvalbumin-positive neurons. We were able to confirm electrophysiological differences between chandelier or basket cells following morphological verification of the neuronal identity (Figure 2). When recorded with standard whole-cell techniques, chandelier (CC) and basket (BC) cells had similar resting membrane potentials $(\mathrm{CC}=-80.8 \pm 3.6 \mathrm{mV}, n=30$; $\mathrm{BC}=-82.7 \pm 5.8 \mathrm{mV}, n=15 ; p=0.20)$ and voltages at spike threshold (defined as $50 \mathrm{mV} / \mathrm{ms} ; \mathrm{CC}=-38.5 \pm 3.8 \mathrm{mV}, n=30$; $\mathrm{BC}=-38.7 \pm 4.8 \mathrm{mV}, n=15 ; p=0.85)$. However a variety of electrophysiological parameters significantly differed between $\mathrm{CCs}$ and BCs (Figures $\mathbf{2 G}, \mathbf{H}$ ), including input resistance $(\mathrm{CC}=129 \pm 62 \mathrm{M} \Omega, n=29 ; \mathrm{BC}=75 \pm 34 \mathrm{M} \Omega, n=14 ; p<0.01)$, rheobase $(\mathrm{CC}=240 \pm 89 \mathrm{pA}, n=27 ; \mathrm{BC}=539 \pm 212 \mathrm{pA}, n=14$; $p<<0.001)$ and membrane time constant (CC $=8.2 \pm 1.9 \mathrm{~ms}$, $n=27 ; \mathrm{BC}=5.1 \pm 1.8 \mathrm{~ms}, n=14 ; p<<0.001)$.

Although CCs and BCs differed markedly in these parameters amongst pooled data, there was nevertheless considerable overlap between individual neurons of either class. Because CCs are sparse and their morphology cannot always be confirmed, we sought to identify them electrophysiologically. Indeed, the response profile of neurons at threshold-level current injections provided a quite reliable means to distinguish CCs and BCs on a cell by cell basis (Figures 2B,E). While CCs exhibited a curved membrane potential response prior to spike onset, basket cells typically showed a flattened depolarizing ramp prior to a spike that occurred with variable onset, as has recently been described and attributed to the presence of axonal Kv1.1 channels (Goldberg et al., 2008). These phenotypic differences were quantified by measuring the latency of the first spike at threshold-level current injections $(\mathrm{CC}=47 \pm 20 \mathrm{~ms}, n=29 ; \mathrm{BC}=195 \pm 129 \mathrm{~ms}, n=18 ; p<<0.001$, Figure 2I). On occasion this depolarizing ramp was not evident, and basket cell spikes occurred at the onset of current injection (Figure 2I). For the majority of cases we were able to use threshold-spiking behavior as the sole indicator of chandelier or basket phenotype. In cases in which the phenotype remained ambiguous, a second, more reliable distinguishing feature used was the subthreshold current-voltage relationship, which was linear or supralinear for CCs but sublinear for BCs (see Materials and Methods, Figures 2C,F). This difference in $I / V$ plots was remarkably robust. Together, the threshold-spiking behavior and subthreshold current-voltage relationship provided nearly $100 \%$ success in identifying a neuron as a chandelier or basket cell.

Based on these results, we conclude that a variety of electrophysiological features can be used to distinguish chandelier and basket cells, which until now have been separable almost exclusively based on their morphology (but note Xu and Callaway, 2009).

\section{DEPOLARIZING EFFECT OF CHANDELIER CELLS ON PYRAMIDAL NEURONS IN GRAMICIDIN RECORDINGS}

After finding a method to reliably target and identify chandelier neurons in living slices, we pursued the question of whether their effect on postsynaptic pyramidal neurons was depolarizing or hyperpolarizing. For this purpose, we recorded from connected CC-pyramidal cell (PC) pairs, focusing on the cortical pyramidal neurons in layer $2 / 3$, whose somata lie in the territories covered by the axons of the chandelier cells we studied, and that should receive GABAergic inputs at their axon initial segment. To examine the postsynaptic effect of chandelier activation, while minimizing the potential interference with intracellular chloride concentration, we used gramicidin patch recordings from the pyramidal neurons. As a control for this series of experiments, we also recorded from basket-pyramidal cell pairs, also with postsynaptic gramicidin recordings.

Direct monosynaptic connections between layer 2 CCs and layer $2 / 3$ pyramidal neurons could readily be found by patching pyramidal cells directly below the recorded chandelier (Figure 3A). At rest $(-80 \pm 5.1 \mathrm{mV}, n=5)$, CC inputs depolarized the pyramidal cell in every single case, and the peak of those PSPs triggered by the CC firing averaged $0.6 \pm 0.2 \mathrm{mV}$ at the soma. The average reversal potential for CC inputs was $-58.3 \pm 9.1 \mathrm{mV}(n=5$; Figure 3B). In addition, two further CC-pyramidal cell pairs, in which gramicidin perforation was inadequate $\left(\mathrm{R}_{\text {series }}>100 \mathrm{M} \Omega\right)$ or in which whole-cell access was obtained unintentionally before establishing $E_{\mathrm{GABA}}$, demonstrated depolarizing responses to CC activation when the pyramidal cell remained at its resting potential (not shown).

In contrast, in the basket-pyramidal cell paired recordings, basket cells elicited PSPs that reversed polarity at $-79.6 \pm 4.9 \mathrm{mV}$ $(n=5, p<0.01$ vs. CC inputs, Figures 3A,B). In three of five BC-PC pairs, the response was purely shunting at rest, i.e., the reversal potential coincided with the resting membrane potential. The other two pairs, which had a common postsynaptic pyramidal cell, had depolarizing responses at rest (not shown), although these depolarizing PSPs became hyperpolarizing at potentials more negative than did any CC PSP. The pyramidal cells receiving basket cell input had a resting potential not significantly different from those receiving CC input $(-86.2 \pm 5.3 \mathrm{mV}, n=4 ; p>0.05$ vs. CC pairs; Figure 3D), indicating the difference in $E_{\mathrm{GABA}}$ between CCs and BCs was not due to differing recording conditions.

In summary, our perforated patch experiments provide evidence for a depolarizing effect of L2/3 cortical chandelier cells. We found no evidence that they have a hyperpolarizing or shunting postsynaptic effect on pyramidal neurons at rest. 
A

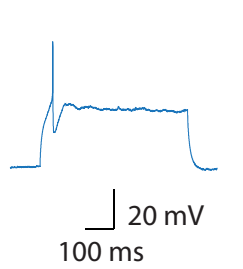

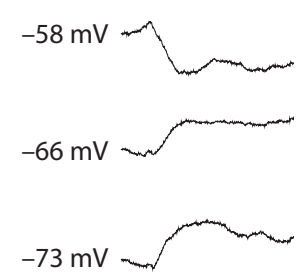

B

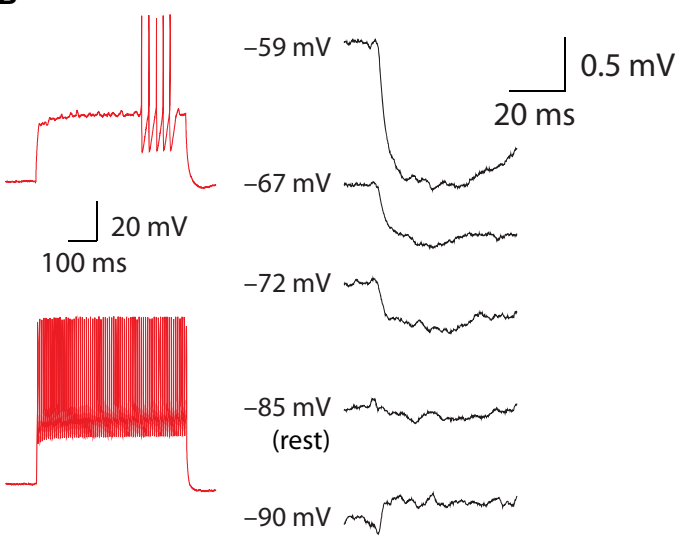

C

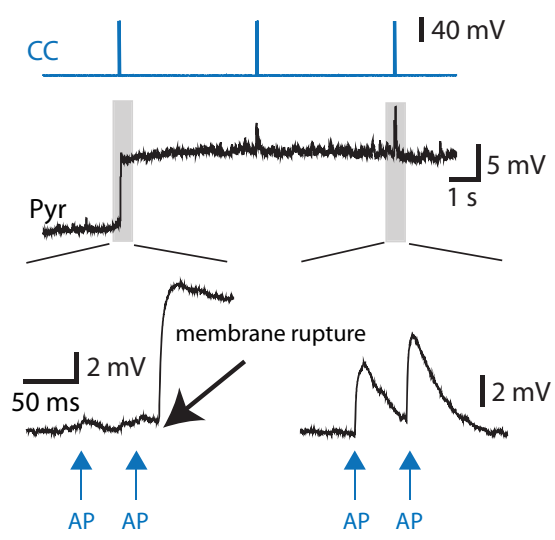

D

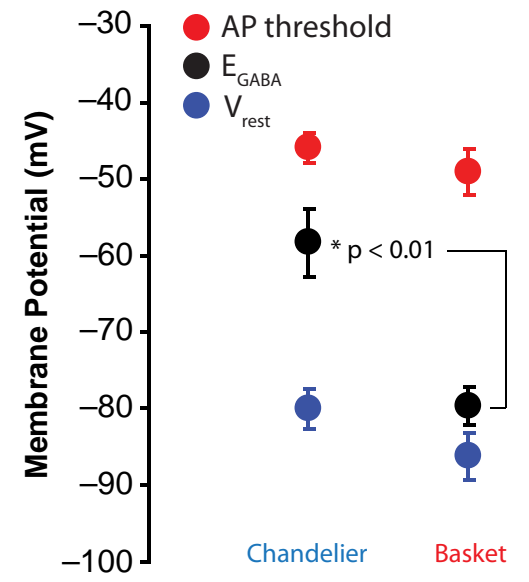

FIGURE 3 | Effect of chandelier neurons on postsynaptic pyramidal cells. (A) Response of pyramidal cell to single chandelier cell action potential. Chandelier cell was identified based on its threshold firing properties (left) (B) As for (A), for presynaptic basket cell. (C) Illustration of the membrane potential jump and enlargement or GABAergic PSPs following transition from perforated-patch to whole-cell configuration. (D) Summary data of all recordings. ${ }^{* *}: p<0.01,{ }^{* *}: p<0.001$.

RECORDING SMALL POSTSYNAPTIC POTENTIALS WITH CELL-ATTACHED RECORDINGS

Given the recent finding of a hyperpolarizing action of hippocampal CCs using extracellular recordings (Glickfeld et al., 2009), we nevertheless sought to confirm our gramicidin-based recordings using a non-invasive recording technique. We chose cell-attached recordings, a technique whereby one does not penetrate the plasma membrane, and therefore presumably does not alter the intracellular ionic composition. Specifically, our goal was to make paired recordings between presynaptic CCs, recorded in whole-cell mode, and postsynaptic pyramidal cells recorded in tight-seal cell-attached mode, which accurately reflects the polarity of voltage fluctuations, if not their amplitude and kinetics (Perkins, 2006).

Since CC-evoked PSPs recorded in the perforated patch configuration were small (typically $<1 \mathrm{mV}$ ) when recorded at the soma, we first ensured that it was actually possible to record small events in tight-seal cell-attached mode. To achieve this, we made simultaneous whole-cell and cell-attached recordings from the same pyramidal neuron (Figure 4A). Before recording changes in membrane potential in response to somatic current injections, we waited for the cell-attached potential to approximate the whole-cell potential (see Materials and Methods). This scenario is met when the seal resistance far outweighs the patch resistance, such that minimal current escapes through the seal resistance, and enables changes in membrane potential to be recorded more accurately by the cell-attached pipette (Perkins, 2006). We found that in response to 50 or $100 \mathrm{~ms}$ current steps injected through the whole-cell pipette, the cell-attached pipette recorded $\sim 25 \%$ of that recorded in the whole-cell pipette (Figure 4A), with kinetics that could be significantly retarded relative to the whole-cell record. Given an average CC PSP amplitude of $0.6 \mathrm{mV}$ at the soma, we could therefore expect 0.1-0.2 mV PSPs to be recorded in cell-attached mode. With averaging of 50 or more sweeps to ensure the signal stood out from the large background noise inherent in cell-attached recordings, it therefore seemed plausible to use tight-seal cell-attached recordings to non-invasively determine the polarity of the effect of a single CC on cortical pyramidal cells. 
A
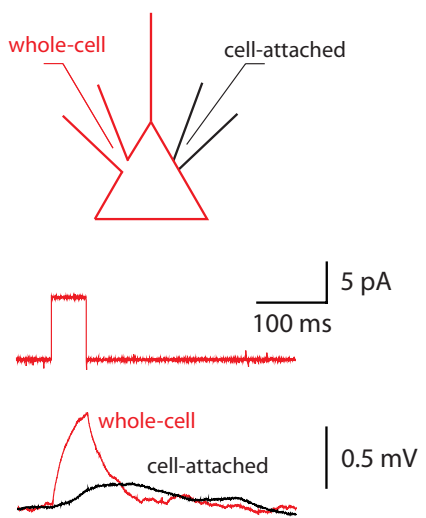

B

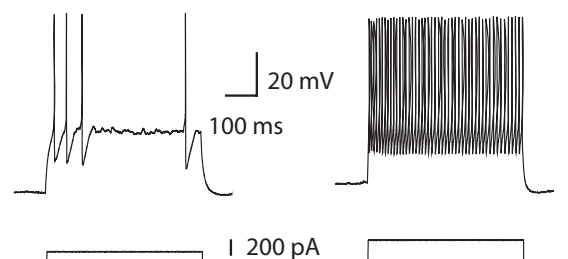

C

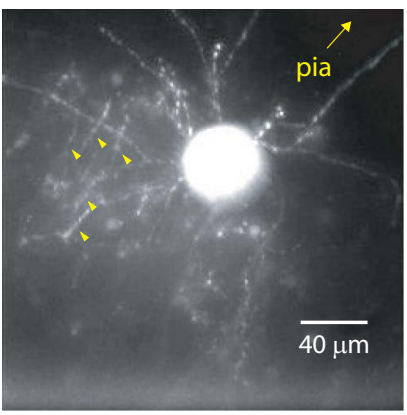

FIGURE 4 | Depolarizing effect of chandelier neurons, in cell-attached recordings. (A) Schematic of recording configuration (top) and traces illustrating cell-attached recording of small membrane potential fluctuations (bottom) (B-E) Physiologically (B) and anatomically (C) identified chandelier cell

\section{DEPOLARIZING EFFECT OF CHANDELIER CELLS ON PYRAMIDAL NEURONS IN CELL-ATTACHED RECORDINGS}

After establishing the feasibility of the approach, we successfully recorded from four connected CC-PC pairs in cell-attached mode (Figures 4B,C). We passed no current through the cell-attached electrode, allowing the cell to remain at its resting membrane potential. The recorded baseline voltage in these pairs, which represents a more depolarized value than the actual membrane potential (Perkins, 2006), was $-88.1 \pm 1.8 \mathrm{mV}(n=4)$. This value, however, is uncorrected for an expected Donnan potential between pipette and cell interior, which arises due to the large differences in $\mathrm{Na}^{+}$and $\mathrm{Cl}^{-}$concentration between the two compartments. In these pairs, a depolarizing response
D
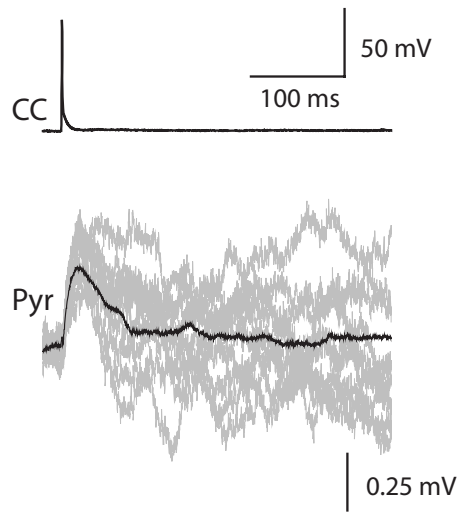

E

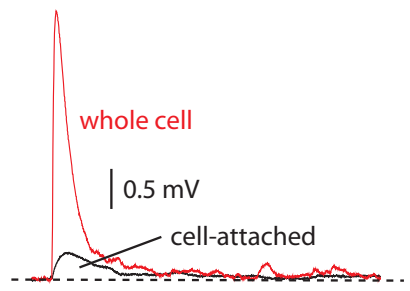

$\mathbf{F}$

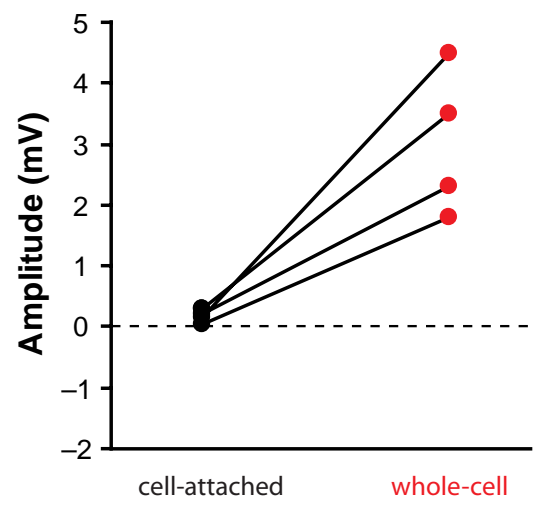

(cartridges highlighted by arrowheads) evoked a depolarizing response from a resting pyramidal neuron recorded in cell-attached mode (D). Subsequent whole-cell recording confirmed synaptic response (E). (F) Summary data for all connected CC-Pyr pairs.

time-locked to the CC spike was clearly evident in the pyramidal cell (Figure 4D). An average onset latency of $1.1 \pm 0.3 \mathrm{~ms}$ confirmed that these were monosynaptic GABAergic events rather than disynaptic glutamatergic PSPs, which can also result from CC activation. As expected, responses were smaller and slower than observed with gramicidin recordings $(0.23 \pm 0.07 \mathrm{mV} ; n=4$; vs. $0.6 \pm 0.2, n=5$ for gramicidin recordings $p<0.001$; latency to peak $=40 \pm 25 \mathrm{~ms} ; n=4$ vs. $9.3 \pm 3.1 \mathrm{~ms} ; n=5$ for gramicidin recordings $p<0.05$ ).

In three of four pairs, whole-cell access was eventually gained, dialyzing the cell with a high chloride solution (ACSF or $150 \mathrm{mM}$ $\mathrm{NaCl}$; see Chavas and Marty, 2003). Although complete dialysis should lead to nearly identical chloride concentrations inside 
and outside the cell, in these three neurons, we were still able to observe depolarizing responses to the CC spike, presumably due to the electrical gradient maintained by the cell, which would favor chloride efflux. Moreover, these three whole-cell recordings confirmed that the depolarizations observed in cell-attached mode were synaptically mediated events triggered by the presynaptic CC (Figures 4E,F).

In addition to these four synaptically-connected CC-PC pairs, in seven additional pairs we did not detect a synaptic connection in cell attached mode. In those seven experiments we used the whole-cell mode to test for potential synaptic connections, since the absence of a response may reflect a purely shunting synapse. In six out of seven pairs with no cell-attached response, we still did not find a synaptic response in whole-cell mode. This argued against the possibility that such pairs were connected through a shunting GABAergic synapse. However, in one pair in which no cell-attached response was evident after averaging, the subsequent whole-cell recording displayed a synaptic connection. There are two possible explanations for this. The first is that the synapse was purely shunting at rest. The second is that the signal was not large enough to emerge from the noise inherent in tight-seal cell-attached recordings. Given that we never observed purely shunting synapses in our gramicidin recordings, and since this particular recording had the lowest quality amongst the connected pairs in cell-attached mode, based on the negativity of the recorded potential and its relation to the seal resistance/patch resistance ratio (this cell $=-76.8 \mathrm{mV}$; other connected pairs $=-88.1 \pm 1.0 \mathrm{mV} ; n=4$ ), we think that the lack of cell-attached response was due to the suboptimal quality of the recording, in which too much current was allowed to pass through the seal resistance.

\section{DISCUSSION \\ DEPOLARIZING EFFECT OF CHANDELIER CELLS ON PYRAMIDAL NEURONS}

Chandelier (or axo-axonic) cells are one of the most distinctive types of GABAergic interneurons in the cortex. Each chandelier cell targets many dozens of pyramidal neurons and each chandelier axon cartridge establishes several synapses in their axonal initial segment. Thus, chandeliers appear ideally suited to control the firing of groups of pyramidal cells, as if they were circuit switches. At the same time, there is confusion about their potential function: while some studies support a depolarizing effect on the pyramidal neurons (Szabadics et al., 2006; Khirug et al., 2008), others instead suggest a hyperpolarizing effect (Glickfeld et al., 2009).

Our data agree well with previous reports on the finding that GABAergic chandelier inputs are depolarizing to resting pyramidal neurons. We first performed minimally-invasive gramicidin recordings, and found no evidence for a hyperpolarizing effect. Furthermore, the depolarizing effect could not simply be an artifact of our recording conditions, since synapses from basket cells were shown to be predominantly shunting at rest. In addition, our cell-attached recordings provide non-invasive, cell-specific evidence that the GABAergic synapse from chandelier cells to pyramidal cells is depolarizing at resting membrane potential, and are in agreement with our gramicidin perforated-patch recordings. We therefore conclude that a depolarizing, possibly excitatory, role must be considered when viewing the function of cortical chandelier cells. Nevertheless, we did not investigate the circuit role of chandelier cells. Also, our data stem solely from a relatively homogeneous population of chandelier cells, at the border between layers 1 and 2, from mouse neocortical area S1, so it is possible that other populations of chandeliers, in other layers, cortical region or species, could behave differently. Finally, all our data were obtained at relatively young ages (P15-23). Even though the circuit is normally considered mature by the third postnatal week, it is possible that there would be differences in our data if it were collected at an older (or younger) age.

\section{TECHNICAL RATIONALE}

Previous reports indicating a depolarized $E_{\mathrm{GABA}}$ at the axon initial segment, either in paired recordings (Szabadics et al., 2006) or with photolysis of caged GABA (Khirug et al., 2008), have used the gramicidin perforated patch technique, which is established as being impermeable to chloride (Kyrozis and Reichling, 1995) and which has therefore been widely used when assessing the postsynaptic properties, and in particular the polarity, of GABAergic synapses. Although less invasive than whole-cell recordings, gramicidin-based recordings nevertheless allow exchange of monovalent cations between the cell's interior and the recording pipette. Since transmembrane chloride gradients are set by cation chloride cotransporters (Blaesse et al., 2009), pipette cations used in gramicidin recordings could indirectly alter $E_{\mathrm{GABA}}$ by affecting the activity of KCC2 and NKCC1, although the magnitude of any such change is likely to be small (Chavas and Marty, 2003).

Because of these potential problems, we complemented our gramicidin recordings with a non-invasive recording technique: tight-seal cell-attached recordings. This technique has not been widely used for recording synaptic potentials, although it was used to measure large-amplitude, network driven events such as giant GABAergic PSPs (Kantrowitz et al., 2005). After confirming our ability to record small events using dual whole-cell/cell-attached recordings, we measured the responses to chandelier cell activation, which were also depolarizing. We believed it possible that the small somatic amplitude of chandelier-triggered PSPs might result in difficulty identifying them in cell-attached recordings. Additionally, since subtle manipulation of the cell membrane potential is difficult with this technique, and since a shunting synapse was a possibility, we established whole-cell mode after testing for the presence of a synaptic connection in the cell-attached configuration.

\section{RELATION WITH PREVIOUS WORK}

Our combined perforated-patch and cell-attached data are in close agreement with reported effects of rat cortical CCs (Szabadics et al., 2006), and are consistent with the axo-somatic-dendritic $E_{\mathrm{GABA}}$ gradient described by Khirug et al. (2008). The possibility that CCs have a depolarizing function nevertheless remains contentious. Indeed, a recent study indicated hippocampal CCs were in fact hyperpolarizing to resting pyramidal cells (Glickfeld et al., 2009). Although this same study found evidence for an excitatory effect of CCs, by means of direct suprathreshold depolarization of the pyramidal neuron, it was argued that such depolarizing effects stood in contrast to what was an overall hyperpolarization of the pyramidal neuron population by the CC, as measured by local field potential recordings. Our data do not agree with their conclusions, and we attempt to explain this discrepancy below, although we welcome further ideas from the readers. 
Glickfeld et al. (2009) suggested that the technique of field recording for assessing the polarity of GABAergic action was advantageous because it was 'insensitive to the vagaries of individual neurons', and also because it was less invasive than intracellular, whole-cell or perforated patch recordings. In our hands, and those of others (Szabadics et al., 2006; Khirug et al., 2008), gramicidin recordings universally revealed depolarizing GABA from chandelier cells. We never measured a hyperpolarizing response at resting membrane potential. This is difficult to reconcile with the suggestion that the depolarizing action is accidental, but could be explained if gramicidin recordings were in some way artifactual. It is not clear how gramicidin recordings may lead to artificially depolarized GABA reversal potentials, or why axonal $E_{\mathrm{GABA}}$ in particular should be affected while somatic and dendritic $E_{\mathrm{GABA}}$ remained unperturbed. One possibility is that by setting $\left[\mathrm{K}^{+}\right]_{i}$ and $\left[\mathrm{Na}^{+}\right]_{i}$ one significantly alters the activity of cation chloride cotransporters, thereby indirectly affecting chloride homeostasis. However, our non-invasive, tight-seal cell-attached recordings from pyramidal neurons postsynaptic to CCs also revealed a universally depolarizing effect. This indicates that the depolarizing action of axonal GABA in gramicidin recordings is not simply an artifact, a conclusion also confirmed by the relatively depolarized reversal of axonal GABA seen in whole-cell recordings (Khirug et al., 2008), and the hyperpolarizing shift seen in reversal potential of a putative amygdala axo-axonic cell synapse immediately after gaining wholecell access (Woodruff and Sah, unpublished results). Indeed, when pooling together both our cell-attached and our gramicidin recordings, 11 out of 11 recordings demonstrated depolarizing chandelier cell inputs. This is unlikely to be a statistical aberration.

A depolarizing effect of CCs or axonal GABA has been described on layer 2/3 cortical pyramidal cells (Szabadics et al., 2006; present study) and hippocampal dentate gyrus cells (Khirug et al., 2008). But because the work of Glickfeld et al. (2009) was conducted in hippocampal CA1, it cannot be ruled out that interareal differences underlie the differing findings. However, since the same study reports a suprathrehsold, excitatory effect of chandelier cells similar to what has been reported in human (Molnar et al., 2008), rat (Szabadics et al., 2006) as well as amygdala (Woodruff et al., 2006), another explanation could result from the conditions under which Glickfeld et al. (2009) performed their experiments, in which the majority of recordings were performed with $3 \mathrm{M} \mathrm{NaCl}$ in the field pipette. Indeed, as acknowledged by the authors, chloride leak from the pipette could contribute to an artificially high extracellular chloride concentration, favoring a hyperpolarizing effect. While it was established that replacing $3 \mathrm{M} \mathrm{NaCl}$ with ACSF had no effect on the hyperpolarizing action of basket cells, this was not demonstrated for chandelier cells, for which this particular control would have been essential. It therefore remains possible that the hyperpolarizing action of hippocampal chandelier cells is due to the presence of molar concentrations of chloride in the field pipette of Glickfeld et al. (2009). This possibility is not inconsistent with the suprathreshold depolarization by chandelier cells reported in the same study-although pyramidal cells in close proximity to the field electrode may have their axonal chloride gradients disturbed by chloride leak, those further from the electrode (which would incidentally have less impact on the recorded field potential) may maintain a gradient favoring chloride efflux, and therefore depolarization. At the same time, it should be noted that in their basket cell recordings, Glickfeld et al. (2009) reported no difference in the amplitude of hyperpolarization with ACSF or $3 \mathrm{M} \mathrm{NaCl}$, which would seem to argue against the possibility for chloride leak to significantly influence local $E_{\mathrm{GABA}}$. Additionally, the chloride leak hypothesis cannot easily explain the fact that a unitary field consistent with a hyperpolarizing synapse could be recorded in dendritic layers after CC activation. A possible explanation for this, however, is that the hyperpolarizing synapse arises via polysynaptic activation of a basket cell (such as in Figure 3C of Glickfeld et al., 2009), although we acknowledge that the response latency in the dendritic field may be too rapid for this phenomenon. In summary, the conflicting data cannot easily be explained by methodological considerations, leaving open the possibility that interareal differences exist between hippocampal CA1 and necortical chandelier cells.

Finally, while the depolarizing effect of cortical CC inputs is statistically valid, we cannot rule out that damaged pyramidal cell axons may be the underlying cause of the depolarization. However, given that we did not specifically target pyramidal neurons located near the slice surface, and given that 11 of 11 neurons received depolarizing inputs, we again think it statistically unlikely that the cause for each one is a damaged axon. Additionally, since basket cell inputs were typically shunting (3/4 postsynaptic neurons), and only $20-50 \mu \mathrm{m}$ from the AIS, we think cellular damage is unlikely to be the cause of the depolarizing effect, particularly given the finding of high levels of NKCC1 at the AIS (Khirug et al., 2008), which provides a potential mechanism for a depolarized axonal $E_{\mathrm{GABA}}$.

\section{POTENTIAL CIRCUIT EFFECTS}

Although we believe our data, together with previous work, convincingly demonstrates a depolarizing effect of CCs on resting pyramidal neurons, it is important to stress that aside from the suprathreshold recruitment of pyramidal neurons, an excitatoryrather than simply depolarizing - effect of CCs is yet to be clearly demonstrated. It is possible, for instance, that the shunt provided by opening of axonal GABA receptors outweighs the depolarization provided by chloride efflux. Even in this case, however, the depolarization will outlast the conductance, theoretically providing an excitatory effect following closure of the conducting channel. Furthermore, all experiments have thus far been performed in vitro under quiescent conditions. In vivo, cortical pyramidal neurons typically receive continuous synaptic bombardment, leading both to a depolarized membrane potential and a much higher conductance state (Destexhe et al., 2003; Watson et al., 2008). Axonal $E_{\text {GABA }}$ has been measured to be $\sim 60$ to $-65 \mathrm{mV}$ (Szabadics. et al., 2006; Khirug et al., 2008; present study), values in the range reported for the average membrane potential of pyramidal neurons in awake animals (Brecht et al., 2004). Although it is possible that during slow-wave sleep and other cortical states CCs will be depolarizing, it is unclear what role they may play in awake animals.

\section{ACKNOWLEDGMENTS}

We thank members of both laboratories for help and comments and anonymous reviewers for their suggestions. Supported by the Kavli Institute for Brain Science, the NEI (Rafael Yuste, EY11787) and the NIMH (Stewart A. Anderson, MH066912 and MH070031). 


\section{REFERENCES}

Ascoli, G. A., Alonso-Nanclares, L., Anderson, S. A., Barrionuevo, G., Benavides-Piccione, R., Burkhalter, A., Buzsâaki, G., Cauli, B., Defelipe, J., Fairâen, A., Feldemeyer, D., Fishell, G., Fregnac, Y., Freund, T F., Gardner, D., Gardner, E.P., Goldberg, J.H., Helmstaedter, M., Hestrin, S., Karube, F., Kisvárday, Z F., Lambolez, B., Lewis, D.A., Marin, O., Markram, H., Muñoz, A., Packer, A., Petersen, C.C., Rockland, K.S., Rossier, J., Rudy, B., Somogyi, P., Staiger,J.F., Tamas, G., Thomson, A M., Toledo-Rodriguez, M., Wang, Y., West, D.C., and Yuste, R. (2008). Petilla terminology: nomenclature of features of GABAergic interneurons of the cerebral cortex. Nat. Rev. Neurosci. 9, 557-568.

Blaesse, P., Airaksinen, M. S., Rivera, C., and Kaila, K. (2009). Cation-chloride cotransporters and neuronal function. Neuron 61, 820-838.

Brecht, M., Schneider, M., Sakmann, B., and Margrie, T. W. (2004). Whisker movements evoked by stimulation of single pyramidal cells in rat motor cortex. Nature 427, 704-710.

Buhl, E. H., Han, Z. S., Lorinczi, Z., Stezhka, V. V., Karnup, S. V., and Somogyi, P. (1994). Physiological properties of anatomically identified axo-axonic cells in the rat hippocampus. J. Neurophysiol. 71, 1289-1307.

Chavas, J., and Marty, A. (2003). Coexistence of excitatory and inhibitory GABA synapses in the cerebellar interneuron network. J. Neurosci. 23, 2019-2031.

Chesler, M., and Kaila, K. (1992). Modulation of $\mathrm{pH}$ by neuronal activity. Trends Neurosci. 15, 396-402.

DeFelipe, J., Hendry, S. H., Jones, E. G., and Schmechel, D. (1985). Variability in the terminations of GABAergic chandelier cell axons on initial segments of pyramidal cell axons in the monkey sensory-motor cortex. J. Comp. Neurol. 231, 364-384.

Destexhe, A., Rudolph, M., and Pare, D. (2003). The high-conductance state of neocortical neurons in vivo. Nat. Rev. Neurosci. 4, 739-751.

Fairen, A., and Valverde, F. (1980). A specialized type of neuron in the visual cortex of cat: a Golgi and electron microscope study of chandelier cells. J. Comp. Neurol. 194, 761-779.

Glickfeld, L. L., Roberts, J. D., Somogyi, P., and Scanziani, M. (2009). Interneurons hyperpolarize pyramidal cells along their entire somatodendritic axis. Nat. Neurosci. 12, 21-23.

Goldberg, E. M., Clark, B. D., Zagha, E., Nahmani, M., Erisir, A., and Rudy, B. (2008). K+ channels at the axon initial segment dampen near-threshold excitability of neocortical fast-spiking GABAergic interneurons. Neuron 58, 387-400.

Inda, M. C., Defelipe, J., and Munoz, A. (2007). The distribution of chandelier cell axon terminals that express the GABA plasma membrane transporter GAT-1 in the human neocortex. Cereb. Cortex 17, 2060-2071.

Jones, E.G. (1975).Varieties and distribution of non-pyramidal cells in the somatic sensory cortex of the squirrel monkey. J. Comp. Neurol. 160, 205-267.

Kantrowitz, J. T., Francis, N. N., Salah, A. and Perkins, K. L. (2005). Synaptic depolarizing GABA response in adults is excitatory and proconvulsive when GABAB receptors are blocked. J. Neurophysiol. 93, 2656-2667.

Khirug, S., Yamada, J., Afzalov, R., Voipio, J., Khiroug, L., and Kaila, K. (2008). GABAergic depolarization of the axon initial segment in cortical principal neurons is caused by the $\mathrm{Na}-\mathrm{K}-2 \mathrm{Cl}$ cotransporter NKCC1. J. Neurosci. 28, 4635-4639.

Kim, Y., and Trussell, L. O. (2007). Ion channels generating complex spikes in cartwheel cells of the dorsal cochlear nucleus. J. Neurophysiol. 97, 1705-1725.

Klausberger, T., Magill, P., Marton, L., Roberts, J., Cobden, P., Buzsaki, G., and Somogyi, P. (2003). Brain-state- and cell-type-specific firing of hippocampal interneurons in vivo. Nature 421, 844-848.

Kyrozis, A., and Reichling, D. B. (1995). Perforated-patch recording with gramicidin avoids artifactual changes in intracellular chloride concentration. J. Neurosci. Methods 57, 27-35.

Lavdas, A. A., Grigoriou, M., Pachnis, V., and Parnavelas, J. G. (1999). The medial ganglionic eminence gives rise to a population of early neurons in the developing cerebral cortex. J. Neurosci. 19, 7881-7888.

Luo, L. (2007). Fly MARCM and mouse MADM: genetic methods of labeling and manipulating single neurons. Brain Res. Rev. 55, 220-227.

Molnar, G., Olah, S., Komlosi, G., Fule, M., Szabadics, J., Varga, C., Barzo, P., and Tamas, G. (2008). Complex events initiated by individual spikes in the human cerebral cortex. PLoS Biol. 6, e222. doi: 10.1371/journal. pbio.0060222.

Pasternack, M., Bountra, C., Voipio, J. and Kaila, K. (1992). Influence of extracellular and intracellular $\mathrm{pH}$ on GABA-gated chloride conductance in crayfish muscle fibres. Neuroscience 47, 921-929.

Perkins, K. L. (2006). Cell-attached voltage-clamp and current-clamp recording and stimulation techniques in brain slices. J. Neurosci. Methods 154, 1-18.

Somogyi,P. (1977).A specific 'axo-axonal' interneuron in the visual cortex of the rat. Brain Res. 136, 345-350.

Szabadics, J., Varga, C., Molnar, G., Olah, S., Barzo, P., and Tamas, G. (2006). Excitatory effect of GABAergic axoaxonic cells in cortical microcircuits. Science 311, 233-235.

Szentagothai, J. (1975). The 'moduleconcept' in cerebral cortex architecture. Brain Res. 95, 475-496.

Szentagothai, J., and Arbib, M. A. (1974) Conceptual models of neural organization. Neurosci. Res. Program Bull.12, 305-510.

Tamas, G., and Szabadics, J. (2004). Summation of unitary IPSPs elicited by identified axo-axonic interneurons. Cereb. Cortex. 14, 823-826.

Watson, B. O., MacLean, J. N., and Yuste, R. (2008). UP states protect ongoing cortical activity from thalamic inputs. PLoS ONE3, e3971. doi: 10.1371/journal.pone.0003971.

Wichterle, H., Garcia-Verdugo, J. M. Herrera, D. G., and Alvarez-Buylla, A. (1999). Young neurons from medial ganglionic eminence disperse in adult and embryonic brain. Nat. Neurosci. 2, 461-466.

Woodruff, A. R., Monyer, H., and Sah, P. (2006). GABAergic excitation in the basolateral amygdala. J. Neurosci. 26, 11881-11887.

Xu, Q., Cobos, I., De La Cruz, E., Rubenstein, J., and Anderson, S. (2004). Origins of cortical interneuron subtypes. J. Neurosci. 24, 2612-2622.

Xu, Q., Tam, M., and Anderson, S. A. (2008). Fate mapping Nkx2.1-lineage cells in the mouse telencephalon. J. Comp. Neurol. 506, 16-29.

$\mathrm{Xu}, \mathrm{X}$., and Callaway, E. M. (2009). Laminar specificity of functional input to distinct types of inhibitory cortical neurons. J. Neurosci. 29, 70-85.

Zaitsev, A. V., Povysheva, N. V., GonzalezBurgos, G., Rotaru, D., Fish, K. N., Krimer, L. S., and Lewis, D. A. (2009). Interneuron diversity in layers $2-3$ of monkey prefrontal cortex. Cereb. Cortex 19, 1597-1615.

Zhu, Y., Stornetta, R. L., and Zhu, J. J. (2004). Chandelier cells control excessive cortical excitation: characteristics of whisker-evoked synaptic responses of layer $2 / 3$ nonpyramidal and pyramidal neurons. J. Neurosci.24, 5101-5108.

Zong, H., Espinosa, J. S., Su, H. H., Muzumdar, M. D., and Luo, L. (2005). Mosaic analysis with double markers in mice. Cell 121, 479-492.

Conflict of Interest Statement: The authors declare that the research was conducted in the absence of any commercial or financial relationships that could be construed as a potential conflict of interest.

Received: 06 August 2009; paper pending published: 29 August 2009; accepted: 30 September 2009; published online: 20 October 2009.

Citation: Woodruff A, Xu Q, Anderson SA and Yuste $R$ (2009) Depolarizing effect of neocortical chandelier neurons. Front. Neural Circuits 3:15. doi: 10.3389/neuro.04.015.2009

Copyright $(2009$ Woodruff, $X u$, Anderson and Yuste. This is an open-access article subject to an exclusive license agreement between the authors and the Frontier Research Foundation, which permits unrestricted use, distribution, and reproduction in any medium, provided the original authors and source are credited. 